\title{
ОСОБЕННОСТИ ОБЩЕСТВЕННОЙ ДИПЛОМАТИИ ГЕРМАНИИ В РОССИИ
}

\begin{abstract}
Аннотация. Важнейшей технологией общественной дипломатии в двадиать первом веке является межкультурная коммуникация, которая служит проводником между культурами и традициями разных народов и государств современного мира. В коние двадиатого - начале двадиать первого века Германия является ключевым стратегическим партнером России из числа стран Европейского Союза. Помимо этого, Германия является своего рода проводником России в Европейском Союзе. В настоящее время российско-германское культурное сотрудничество развивается довольно успешно и поступательно. Методология исследования включает в себя системный, структурно-функииональный, сравнительно-политический и культурноцивилизационный подходь, методы индукиии, дедукиии, анализа, синтеза, наблюдения. Российско-германское культурное сотрудничество вписывается в реализуемую обеими сторонами линию на историческое примирение, стимулирование общения между нашими народами и их углубленное знакомство с культурой, духовными иенностями России и Германии. Общественная дипломатия Германии направлена на формирование положительного имиджа Германии и распространению с помощью межкультурной коммуникации немеиких иенностей в России для укрепления стратегического партнерства менду странами.
\end{abstract}

Ключевые слова: политика, управление, общественная дипломатия, Германия, стратегическое сотрудничество, межкультурная коммуникаиия, Россия, ЕС, безопасность, политический режим

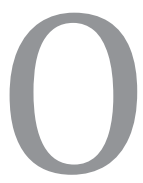

бщественная дипломатия как система прямого взаимодействия государств с обществами зарубежных стран существует столько же, сколько сами государства, но особый интерес к этой сфере появился сравнительно недавно. Одно из главных орудий в «холодной войне» - общественная дипломатия - утратила привлекательность в 1990-х годах, однако затем вновь заинтересовала исследователей и практиков после трагедии 11 сентября 2001 года. В условиях изменившегося глобального коммуникационного и мирополитического контекста традиционные подходы к общественной дипломатии оказались неэффективны. Это стало причиной развития концепции «новой общественной дипломатии», направленной на сотрудничество между обществами ${ }^{1}$.

Одной из важных теоретических призм в изучении общественной дипломатии остается универсальная для социально-гуманитарного знания дихотомия «соперничество - сотрудничество». Применительно к общественной дипломатии

\footnotetext{
${ }^{1}$ Долинский А. Дискурс о публичной дипломатии. // Международные процессы. Том 9, №1(25). Январь-апрель 2011. - C.1
}

она была впервые наиболее полно разработана в трудах британского исследователя и практика Марка Леонарда. Он предложил использовать время как один из параметров анализа при изучении особенностей общественной дипломатии. Леонард выделяет в ней три измерения: реактивное, проактивное и установление отношений. Реактивное - это работа по реагированию на уже произошедшие события, во многом похожая на работу средств массовой информации и пресс-служб. На деле она представляет собой комментарии от политиков и дипломатов по поводу действий страны, работу пресс-службы посольств, распространение новостных сообщений средствами зарубежного вещания. Проактивное - это транслирование собственного сообщения, формирование мнений. Подобная работа может делаться как через средства зарубежного вещания, так и с помощью методов культурной дипломатии или мероприятий в посольствах. Наконец, третье измерение - это выстраивание отношений, которое подразумевает двусторонность, взаимное уважение к ценностям и достижениям других обществ. Соответственно, первое измерение рассчитано, 


\section{Тренды и управление 3(7) • 2014}

по мнению Леонарда, на дни и часы, второе - на недели и месяцы, а третье - на годы. ${ }^{2}$

Таким образом, общественная дипломатия создает сложную, многогранную, долгосрочную совокупность связанных со страной ассоциаций, тем самым, препятствуя утверждению упрощенного стереотипного восприятия образа страны в других странах. ${ }^{3}$ Цели общественной дипломатии достигаются, прежде всего, путем изучения настроений иностранного общественного мнения, информирования его и, в частности, воздействия на так называемые stakeholders, т.е. тех, кто это мнение формирует. Это могут быть политики, журналисты, аналитики, бизнесмены, артисты ${ }^{4}$.

Прежде чем перейти к анализу общественной дипломатии Германии автор хотел бы рассмотреть внешнеполитическую концепцию Германии в период ее объединения.

Объединение Германии изменило базовые условия послевоенной «траектории». Во-первых, оно положило конец жесткой биполярности, которая проходила непосредственно «по телу» страны и поэтому значительно нарушала установленные внешнеполитические координаты. Во-вторых, оно сопровождалось весьма спорным представлением о росте германской мощи (Machtzuwachs). И, в-третьих, нужно было пересмотреть уроки истории, поскольку «поворот на Восток» повлек за собой необходимость энергичного восстановления дружественных отношений ${ }^{5}$.

Весьма в духе помолодевших реалистических концепций период канцлерства Г. Шредера (1998 - 2005 гг.) может отражать «созревание» Германии в самом чистом виде, но, судя по позиции его последователя, никоим образом не продолжение эволюции. Именно явно экстравагантная политика Шредера по отношению к России, начиная с 2002 г., наилучшим образом помогала следовать его

\footnotetext{
${ }^{2}$ Mark Leonard, Catherine Stead, Conrad Smewing. Public Diplomacy. London: The Foreign Policy Centre, 2002. P. 10-11.

${ }^{3}$ Виноградова Е.А. Общественная дипломатия стран АЛБА перед вызовами глобализации. Государственное управление. Электронный вестник. Выпуск №44. Июнь 2014 г.

${ }^{4}$ Глаголев В. С., Бирюков Н.И., Зубина Н.Н. Межкультурная коммуникация в условиях глобализации. - М.: Проспект, 2010. - C.186.

${ }^{5}$ Шпангер Х. Германия и Россия: нежданное стратегическое партнерство. Мировая экономика и международные отношения, №6, Июнь 2010. - С. 41.
}

«немецкому пути» «уверенной защиты интересов» Германии (данный термин вошел в политический лексикон лишь после объединения страны). Руководствуясь реалистическим подходом, это можно рассматривать как естественное следствие изменений в международных отношениях после холодной войны и роста германской мощи, которое стало результатом возобновления многополярности и «нормальной анархии», заменивших биполярность. В этих условиях объединенная Германия могла бы вновь действовать как великая европейская держава, во взаимодействии с другими великими державами, в первую очередь с Россией ${ }^{6}$

С точки зрения перспективы гражданского торгового государства, стратегическое партнерство с Россией не обязательно влечет за собой отход от установленных принципов, но может быть оправдано как легитимный и необходимый инструмент для использования экономических возможностей в мировой конкуренции.

Тем не менее, в силу объективных реалий постбиполярного мира, во внешнеполитической табели о рангах правительства ФРГ Россия занимает 4-е место. Немцы продолжают рассматривать ее как стратегического партнера (употребляя иногда термин «привилегированное партнерство»), без которого и, тем более, вопреки которому невозможно решение ни региональных, ни глобальных вызовов и проблем.

Здесь следует отметить, двоякость политики Германии в области общественной дипломатии по отношению к России. С одной стороны, имидж России в Германии находится под постоянным обстрелом со стороны немецких средств массовой информации, в то время как РФ с беспомощным видом разводит руками, ссылаясь на нехватку средств.

Выделяются деньги на финансирование телеканала «Россия сегодня», который немцы, в силу незнания языка (на немецком языке вещание не ведется), попросту не смотрят, а на то, чтобы финансировать пропагандистскую работу в области образования, культуры и науки с привлечением высококлассных специалистов со знанием немец${ }^{6}$ Schollgen G. Der Auftritt. Deutschlands Ruckkehr auf die
Weltbuhne. Berlin, 2004. S. 11,130,133. 


\section{Мировой порядок}

кого языка, объединенных в Обществе РоссияГермания, - нет ${ }^{7}$.

С другой стороны корректором общественного мнения о Германии и ее СМИ служит посольство Германии в России.

Так посол Германии в своем интервью российскому информационному агентству Итар-Тасс подчеркнул, что «не замечал никакого рода антироссийских публикаций в германской прессе. Возможно, были и критические статьи, но это скорее всего демонстрирует то обстоятельство, что интерес к России в Германии сейчас крайне высок. Россия для нас является важным партнером по целому ряду вопросов. И резолюция, которую бундестаг ФРГ принял в прошедшую пятницу, демонстрирует - насколько в политической сфере, в сфере международных и экономических отношений важна для нас Россия. Ваша страна вступила в ВТО, Россия сближается с Европейским союзом. И это для нас крайне важно» ${ }^{8}$.

Помимо этого посол Германии Ульрих Бранденбург проводит активную обществопедагогическую работу в российских учебных заведениях.

Ярким примером может послужить его открытая лекция, проведенная 11 декабря 2012 года на философском факультете МГУ им. М.В. Ломоносова в которой он говорил о культурных связях между нашими странами в историческом ключе.

В этой связи важным направлением немецкой общественной дипломатии в России служит корректировка агрессивного имиджа Германии, которая сложилась в российском общественном мнении после Второй мировой Войны.
Помимо работы посольства Германии в РФ в этом направлении под патронатом МИД немцы активно продвигают свой имидж, опираясь на такие авторитетные организации, как Германская служба академических обменов, Институт им. Гете, близкие к ведущим партиям фонды (все они имеют представительства в Москве) и др.

Подчеркивая важность сотрудничества с Россией на сайте МИДА Германии есть русскоязычная версия и ссылки на различные германороссийские общественные организации.

Имидж Германии в России в последние годы стал сравнительно высок. Данные практически всех опросов общественного мнения за последние годы показывают, что Германия в глазах россиян остается одним из главных наших союзников. Например, согласно опросу («Назовите пять стран, которые вы могли бы назвать наиболее близкими друзьями, союзниками России»), проведенному аналитическим центром Юрия Левады 11-14 мая 2007 г., Германия находится на третьем месте (24\%), уступая лишь Казахстану (39\%) и Белоруссии (38\%), а враждебно настроенной ее считают всего лишь $2 \%$ россиян ${ }^{9}$.

Таким образом, подводя итог этого раздела, отметим, что важнейшим направлением общественной дипломатии Германии в отношении России является корректировка агрессивного имиджа, который сложился в России после Второй мировой войны и распространение немецких культурных ценностей в России, что будет способствовать установление более прочных стратегических контактов между двумя странами. В этой связи важной составляющей общественной дипломатии Германии является межкультурная коммуникация.

\footnotetext{
${ }^{7}$ Павлов Н. Россия и Германия перед вызовами XXI века // Мировая экономика и международные отношения, №6, Июнь 2012. - С. 40.

${ }^{8}$ Интерес к России в Германии сейчас крайне высок - посол ФРГ в России Ульрих Бранденбург - интервью (13.11.12.) [Электронный pecypc]. - URL: http://www.itar-tass.com/ c49/570471.html (дата обращения: 2.03.2013)
}

\footnotetext{
${ }^{9}$ Голов А.А. Друзья и недруги России в оценках россиян. [Электронный ресурс]. - URL: www.polit.ru/ research/2007/06/05/countries.html (дата обращения 14.02.2013)
} 


\section{Тренды и управление 3(7) • 2014}

\section{Библиография}

1. Виноградова Е.А. Общественная дипломатия стран АЛБА перед вызовами глобализации. Государственное управление. Электронный вестник. Выпуск №44. Июнь 2014 г.

2. Глаголев В. С., Бирюков Н.И., Зубина Н.Н. Межкультурная коммуникация в условиях глобализации. - М.: Проспект, 2010.

3. Голов А.А. Друзья и недруги России в оценках россиян. [Электронный pecypc]. - URL: www.polit. ru/research/2007/06/05/countries.html (дата обращения 14.02.2013)

4. Долинский А. Дискурс о публичной дипломатии. // Международные процессы. Том 9, №1(25). Январь-апрель 2011.

5. Интерес к России в Германии сейчас крайне высок-посол ФРГ в России Ульрих Бранденбург - интервью(13.11.12.) [Электронный ресурс]. - URL: http://www.itar-tass.com/c49/570471.html (дата обращения: 2.03.2013)

6. Павлов Н. Россия и Германия перед вызовами XXI века // Мировая экономика и международные отношения, №6, Июнь 2012. -С. 40.

7. Шпангер X. Германия и Россия: нежданное стратегическое партнерство. Мировая экономика и международные отношения, №6, Июнь 2010.

8. Mark Leonard, Catherine Stead, Conrad Smewing. Public Diplomacy. London: The Foreign Policy Centre, 2002.

9. Schollgen G. Der Auftritt. Deutschlands Ruckkehr auf die Weltbuhne. Berlin, 2004.

10. Манойло А.В. Модель информационно-психологической операции в международных конфликтах. // Право и политика.-2008.-№6. - С.1387-1394.

11. Манойло А.В. Управление конфликтами. Модель психологической операции. // Акмеология.-2009.№1. - С. 64-74.

12. Манойло А.В. Информационное противоборство в условиях психологической войны. // Закон и право.-2003.-№12. - С. 31-34.

13. Манойло А.В. Несиловое регулирование международных конфликтов. Культурно-цивилизационные парадигмы. // Космополис.-2008.-№2. - С.168-174.

14. Манойло А.В. Психологические операции: модели и технологии управления конфликтами. // Политэкс (Политическая экспертиза).-2008.-№3.-С. 62-73.

15. Манойло А.В. Психологические операции США в Ираке. // Космополис.-2008.-№1. - С.124-128.

16. Манойло А.В. Модель информационно-психологической операции в международных конфликтах // Право и политика.-2008.-№6. - С.1387-1394.

17. Зольнова М.Г. Общественная дипломатия Швеции // Тренды и управление. - 2014. - 2. - С. 137 - 146. DOI: $10.7256 / 2307-9118.2014 .2 .12407$.

18. Зворыгина М.A. Российский федерализм и зарубежный опыт консоциальной демократии // Тренды и управление. - 2014. - 1. - C. 14 - 20. DOI: 10.7256/2307-9118.2014.1.12384.

19. Манойло А.В. О противодействии распространению идеологии «цветных революций»в университетской студенческой среде // Международные отношения. - 2013. - 4. - C. 420 - 423. DOI: 10.7256/2305-560Х.2013.4.9755.

20. Нейматова А.Я. МИД России и новая публичная дипломатия // Международные отношения. - 2013. - 1. - C. 80 - 85. DOI: 10.7256/2305-560Х.2013.01.9.

21. Карпович О.Г. Современные концепции и модели управления международными конфликтами (сравнительный политологический анализ) // Национальная безопасность / nota bene. - 2013. - 4. - C. 605 - 612. DOI: 10.7256/2073-8560.2013.4.6434.

22. Егоров В.Г. Режимная трансформация постсоветских независимых государств // Международные отношения. - 2013. - 4. - C. 452 - 470. DOI: 10.7256/2305-560X.2013.4.9398.

23. Гушер А.И. Экспертная оценка политико-экономической ситуации в Украине // Международные отношения. - 2014. - 3. - С. 326 - 331. DOI: 10.7256/2305-560X.2014.3.11815. 


\section{Мировой порядок}

24. Манойло А.В. О противодействии цветным революциям // Международные отношения. - 2014 . - 3. - C. 332 - 363. DOI: 10.7256/2305-560X.2014.3.12060.

25. Будаев А.В. Основные подходы к использованию «мягкой силы»в интересах реализации внешней политики Российской Федерации // Тренды и управление. - 2014. - 2. - C. 175 - 187. DOI: 10.7256/2307-9118.2014.2.11784.

26. Спиридонов В.В. Финансово-экономические причины политического кризиса на Украине. Взгляд через призму анализа банковской системы страны // Международные отношения. - 2014. - 3. - С. 398 - 405. DOI: 10.7256/2305-560Х.2014.3.11740.

27. Спиридонов В.В. Экономический подход к анализу причин политического конфликта на Украине // Международные отношения. - 2014. - 2. - C. 254 - 261. DOI: 10.7256/2305-560X.2014.2.11527.

28. С. А. Кондаков Трубопроводная дипломатия России // Международные отношения. - 2012. - 1. - С. 128 - 138.

\section{References}

1. Vinogradova E.A. Obshchestvennaya diplomatiya stran ALBA pered vyzovami globalizatsii. Gosudarstvennoe upravlenie. Elektronnyi vestnik. Vypusk №44. Iyun’ $2014 \mathrm{~g}$.

2. Glagolev V. S., Biryukov N.I., Zubina N.N. Mezhkul'turnaya kommunikatsiya v usloviyakh globalizatsii. - M.: Prospekt, 2010.

3. Golov A.A. Druz'ya i nedrugi Rossii v otsenkakh rossiyan. [Elektronnyi resurs]. - URL: www.polit.ru/research/2007/06/05/countries.html (data obrashcheniya 14.02.2013)

4. Dolinskii A. Diskurs o publichnoi diplomatii. // Mezhdunarodnye protsessy. Tom 9, №1(25). Yanvar'-aprel’ 2011.

5. Interes k Rossii v Germanii seichas kraine vysok-posol FRG v Rossii Ul'rikh Brandenburg - interv'yu(13.11.12.) [Elektronnyi resurs]. - URL: http://www.itar-tass.com/c49/570471.html (data obrashcheniya: 2.03.2013)

6. Pavlov N. Rossiya i Germaniya pered vyzovami XXI veka // Mirovaya ekonomika i mezhdunarodnye otnosheniya, №6, Iyun' 2012. -S. 40.

7. Shpanger Kh. Germaniya i Rossiya: nezhdannoe strategicheskoe partnerstvo. Mirovaya ekonomika i mezhdunarodnye otnosheniya, №6, Iyun' 2010.

8. Mark Leonard, Catherine Stead, Conrad Smewing. Public Diplomacy. London: The Foreign Policy Centre, 2002.

9. Schollgen G. Der Auftritt. Deutschlands Ruckkehr auf die Weltbuhne. Berlin, 2004.

10. Manoilo A.V. Model' informatsionno-psikhologicheskoi operatsii v mezhdunarodnykh konfliktakh. // Pravo i politika.-2008.-№6. - S.1387-1394.

11. Manoilo A.V. Upravlenie konfliktami. Model' psikhologicheskoi operatsii. // Akmeologiya.-2009.-№1. - S. 64-74.

12. Manoilo A.V. Informatsionnoe protivoborstvo v usloviyakh psikhologicheskoi voiny. // Zakon i pravo.-2003.№12. - S. 31-34.

13. Manoilo A.V. Nesilovoe regulirovanie mezhdunarodnykh konfliktov. Kul'turno-tsivilizatsionnye paradigmy. // Kosmopolis.-2008.-№2. - S.168-174.

14. Manoilo A.V. Psikhologicheskie operatsii: modeli i tekhnologii upravleniya konfliktami. // Politeks (Politicheskaya ekspertiza).-2008.-№3.-S. 62-73.

15. Manoilo A.V. Psikhologicheskie operatsii SShA v Irake. // Kosmopolis.-2008.-№1. - S.124-128.

16. Manoilo A.V. Model' informatsionno-psikhologicheskoi operatsii v mezhdunarodnykh konfliktakh // Pravo i politika.-2008.-№6. - S.1387-1394.

17. Zol'nova M.G. Obshchestvennaya diplomatiya Shvetsii // Trendy i upravlenie. - 2014. - 2. - C. 137 - 146. DOI: 10.7256/2307-9118.2014.2.12407.

18. Zvorygina M.A. Rossiiskii federalizm i zarubezhnyi opyt konsotsial'noi demokratii // Trendy i upravlenie. - 2014. - 1. - C. 14 - 20. DOI: 10.7256/2307-9118.2014.1.12384. 


\section{Тренды и управление 3(7) • 2014}

19. Manoilo A.V. O protivodeistvii rasprostraneniyu ideologii «tsvetnykh revolyutsii» v universitetskoi studencheskoi srede // Mezhdunarodnye otnosheniya. - 2013. - 4. - C. 420 - 423. DOI: 10.7256/2305-560X.2013.4.9755.

20. Neimatova A.Ya. MID Rossii i novaya publichnaya diplomatiya // Mezhdunarodnye otnosheniya. - 2013. - 1. - C. 80 - 85. DOI: 10.7256/2305-560X.2013.01.9.

21. Karpovich O.G. Sovremennye kontseptsii i modeli upravleniya mezhdunarodnymi konfliktami (sravnitel'nyi politologicheskii analiz) // Natsional'naya bezopasnost' / nota bene. - 2013. - 4. - C. 605 - 612. DOI: 10.7256/2073-8560.2013.4.6434.

22. Egorov V.G. Rezhimnaya transformatsiya postsovetskikh nezavisimykh gosudarstv // Mezhdunarodnye otnosheniya. - 2013. - 4. - C. 452 - 470. DOI: 10.7256/2305-560X.2013.4.9398.

23. Gusher A.I. Ekspertnaya otsenka politiko-ekonomicheskoi situatsii v Ukraine // Mezhdunarodnye otnosheniya. - 2014. - 3. - C. 326 - 331. DOI: 10.7256/2305-560X.2014.3.11815.

24. Manoilo A.V. O protivodeistvii tsvetnym revolyutsiyam // Mezhdunarodnye otnosheniya. - 2014. - 3. - C. 332 - 363. DOI: 10.7256/2305-560X.2014.3.12060.

25. Budaev A.V. Osnovnye podkhody k ispol'zovaniyu «myagkoi sily» v interesakh realizatsii vneshnei politiki Rossiiskoi Federatsii // Trendy i upravlenie. - 2014. - 2. - C. 175 - 187. DOI: 10.7256/2307-9118.2014.2.11784.

26. Spiridonov V.V. Finansovo-ekonomicheskie prichiny politicheskogo krizisa na Ukraine. Vzglyad cherez prizmu analiza bankovskoi sistemy strany // Mezhdunarodnye otnosheniya. - 2014. - 3. - C. 398 - 405. DOI: 10.7256/2305-560X.2014.3.11740.

27. Spiridonov V.V. Ekonomicheskii podkhod k analizu prichin politicheskogo konflikta na Ukraine // Mezhdunarodnye otnosheniya. - 2014. - 2. - C. 254 - 261. DOI: 10.7256/2305-560X.2014.2.11527.

28. S. A. Kondakov Truboprovodnaya diplomatiya Rossii // Mezhdunarodnye otnosheniya. - 2012. - 1. - C. 128 $-138$. 